\title{
POLÍTICAS PÚBLICAS DE ESPORTE E LAZER PARA PESSOAS COM DEFICIÊNCIA
}

\author{
SPORT AND LEISURE POLICIES FOR PEOPLE WITH DISABILITIES
}

\author{
POLITICAS PÚBLICAS DE DEPORTE Y OCIO PARA PERSONAS CON \\ DISCAPACIDAD
}

\author{
Andresa Caravage*, Fátima Corrêa Oliver**
}

\begin{abstract}
Palavras chave: Esportes.

Atividades de lazer.

Defesa das pessoas com deficiência.

Política pública.

Resumo: Estudos brasileiros sobre políticas públicas de esporte e lazer são incipientes, principalmente aqueles que abordam as pessoas com deficiência. A temática é complexa e, embora este estudo traga o contexto específico de um município do estado de São Paulo, buscou-se uma visão ampliada sobre a constituição dos programas esportivos e demais políticas públicas a partir da compreensão da organização (polity), das disputas internas (politics), da política pública resultante (policy) e dos atores que compõem a rede (policy network). No mapeamento e entrevistas com gestores e profissionais, foram identificados três programas e cinco modalidades adaptadas às pessoas com deficiência. Mesmo sem uma política intersetorial articulada e as relações entre os atores sendo, predominantemente, informais até então, o surgimento de demanda, a organização social e a sensibilidade dos órgãos competentes para articularem condições, instituições e pessoas capazes do enfrentamento da questão foram pontos-chave para 0 desenvolvimento das ações.
\end{abstract}

\section{Keywords:}

Sports.

Leisure activities.

Handicapped

advocacy.

Public Policy.

\begin{abstract}
Brazilian studies about policies for sport and leisure are incipient, especially those addressing people with disabilities. The subject is complex and although this study approaches the specific context of a municipality in the state of São Paulo, it sought to provide an expanded view on the constitution of sports programs and other public policies by understanding the organization (polity), internal disputes (politics), the resulting guidelines (policy), and the actors that make up the network (policy network). Mapping and interviews with managers and professionals found three programs and five sports adapted to people with disabilities. Even without coordinated inter-sector policies and with relationships among actors being predominantly informal so far, the emergence of demand, social organization, and sensitivity of competent agencies to coordinate conditions, institutions and people capable of facing the issue were the key points for developing the actions.
\end{abstract}

Palabras clave: Deportes.

Actividades recreativas. Defensa de las Personas con Discapacidad. Política Pública.
Resumen: Resumen: Los estudios brasileños sobre políticas públicas de deporte y ocio son incipientes, especialmente aquellos sobre las personas con discapacidad. El tema es complejo, y aunque este artículo aporte el contexto específico de un municipio del estado de São Paulo, se buscó una visión ampliada sobre la constitución de los programas deportivos y demás políticas públicas desde la comprensión de la organización (polity), de las disputas internas (politics), de la política pública resultante (policy) y de los actores que componen la red (policy network). En el mapeo y entrevistas con los gestores y profesionales se identificaron tres programas y cinco modalidades adaptadas para personas con discapacidad. Incluso sin una política intersectorial articulada y pese a que las relaciones entre los actores son, predominantemente, informales, el surgimiento de la demanda, la organización social y la sensibilidad de los órganos competentes para articular condiciones, instituciones y personas capaces de enfrentar el problema fueron puntos clave para el desarrollo de acciones.
*Universidade Federal de São Carlos. São Carlos, SP, Brasil.

E-mail: andresa.caravage@gmail.com

**Universidade de São Paulo. São Paulo, SP, Brasil. E-mail: fcoliver@ usp.br

Recebido em: 05-06-2017 Aprovado em: 19-09-2018

DOI: https://doi.org/10.22456/1982-8918.73957 (c) (1) (8) Licence 


\section{INTRODUÇÃO}

Os estudos nos subcampos científico e acadêmico das políticas públicas de esporte e lazer no Brasil são recentes, datam dos anos 1980, período de abertura democrática no país (STAREPRAVO, 2011).

A estrutura político-administrativa do esporte, que teve sua organização iniciada na década de 1930, como forma de construção e difusão do nacionalismo, passou por diversas mudanças e ressignificações até a criação do Ministério do Esporte, em 2003 (STAREPRAVO, 2011).

A partir da Constituição Federal de 1988, o esporte passa a ser considerado direito social e dever do Estado. Contudo, após constante pressão das entidades esportivas e do mercado, o Estado deixa o protagonismo das ações no setor (MATIAS et al., 2015).

Nos últimos anos, o esporte no Brasil tem atraído maior atenção, em parte, devido aos megaeventos esportivos que sediou: Jogos Pan-Americanos e Parapan-Americanos 2007, Jogos Militares 2011, Copa das Confederações 2013, Copa do Mundo 2014, Jogos Olímpicos e Paralímpicos 2016. Nesse período, estruturaram-se as políticas e programas de esporte e lazer, como: o Programa Segundo Tempo e Esporte e Lazer na Cidade (2003), Bolsa-Atleta (2005), Lei de Incentivo ao Esporte (2006), Mais Educação (2007), Programa de Incorporação de Atletas de Alto Rendimento às Forças Armadas Brasileiras (2008), Lei Paulista de Incentivo ao Esporte (2010), Bolsa-Pódio (2011), Plano Brasil Medalhas (2012), Atleta na Escola (2013) e os Centros de Iniciação ao Esporte (2013).

Com relação à organização, gestão e desenvolvimento do esporte, três ações têm sido fundamentais: 1. A realização das Conferências Nacionais de Esporte (2004, 2007 e 2010), que pretendem promover a democratização do esporte e a participação popular; 2. A criação do Centro de Desenvolvimento do Esporte e do Lazer - Rede Cedes (2004), que visa fomentar a gestão de políticas públicas de esporte e lazer por meio de referenciais teóricos produzidos por grupos de pesquisa acadêmica; 3. A criação da Rede de Treinamento (2011), que visa interligar toda a infraestrutura esportiva do país.

$\mathrm{O}$ atual contexto esportivo brasileiro tem contribuído para o crescente interesse pelas políticas de esporte e lazer, inclusive entre pesquisadores da Ciência Política, Sociologia e Economia. Esse aumento foi notado por Starepravo, Nunes e Marchi Júnior (2009) ao analisarem trabalhos publicados no XV Congresso Brasileiro de Ciências do Esporte, no qual a maioria eram relatos de experiência sem diálogo consistente com a literatura. Naqueles mais estruturados, a discussão se dava em torno da macroestrutura econômica, com postura crítica ao modelo neoliberal de gestão, pois "[...] este modelo, dado os interesses do capital, leva o Estado a intervir cada vez menos no âmbito social, repassando esta função a setores organizados da sociedade civil" (STAREPRAVO; NUNES; MARCHI JÚNIOR, 2009, p.10). Embora os autores reconheçam essa questão, discutem sobre a falta de referencial teórico e metodológico dos estudos e o fato dos dados de pesquisa apresentados ficarem em segundo plano.

Recentemente, algumas pesquisas publicadas têm buscado suprir essa lacuna ao apresentar uma proposta teórico-metodológica de análise das políticas de esporte e lazer com base em referenciais das ciências sociais e políticas (STAREPRAVO; SOUZA; MARCHI JÚNIOR, 2011). Tanto a teoria dos jogos competitivos do sociólogo alemão Norbert Elias 
quanto o pensamento do sociólogo francês Pierre Bourdieu têm sido utilizados como lentes de análise das políticas públicas de esporte e lazer (STAREPRAVO, 2011).

Entende-se que há uma lacuna quanto aos estudos no subcampo das políticas públicas de esporte e lazer $^{1} \mathrm{e}$, principalmente, naquelas relativas às pessoas com deficiência. As reflexões aqui apresentadas procuram, como salientam Starepravo, Souza e Marchi Júnior (2011), pensar as políticas públicas para além da política pública em si, do programa ou da iniciativa pública como fenômenos estanques e isolados do contexto social. Afinal,

\begin{abstract}
A política pública muitas vezes é apenas a parte mais visível de todo um processo desenvolvido num espaço social específico, que comporta disputas, relações, alianças, decisões estratégicas e também não planejadas. Em suma, escrever sobre políticas públicas de esporte e lazer requer mapear o espaço social onde estas são produzidas, avançar no entendimento das relações entre os agentes, até finalmente compreender quais as políticas que foram efetivadas, aquelas que foram preteridas, as que obtiveram êxito e aquelas que não passaram de propostas (STAREPRAVO, 2014, p.34, grifo nosso).
\end{abstract}

Neste estudo, buscou-se compreender como se estruturam as políticas de esporte e lazer para as pessoas com deficiência em dado município, a partir do mapeamento dos espaços, atores e suas inter-relações. Ressalta-se que a tarefa de analisar o subcampo é "[... complexa [...] e por vezes limitada, dada a posição de quem está observando ou o lugar de onde se está falando" (STAREPRAVO; SOUZA; MARCHI JÚNIOR, 2011, p.235). Indicada parte das limitações e complexidade, o artigo traz à reflexão recorte de uma dissertação de mestrado, na tentativa de contribuir para a leitura crítica das macro e microestruturas de proposição e desenvolvimento de políticas públicas de esporte e lazer para pessoas com deficiência.

\title{
2 POLÍTICAS PÚBLICAS, ESPORTE E LAZER E AS PESSOAS COM DEFICIÊNCIA
}

Políticas públicas tratam dos conteúdos concreto e simbólico "[...] de decisões políticas e do processo de construção e atuação dessas decisões" (SECCHI, 2013, p.1). A entrada de determinada questão na agenda política se dá em resposta ao enfrentamento de um problema público, entendido como coletivamente relevante. A política pública resultante pode ser entendida como a diretriz criada para a resolução desse problema.

Para Souza, política pública é "[...] o campo do conhecimento que busca, ao mesmo tempo, colocar o 'governo em ação' e/ou analisar essa ação (variável independente) e, quando necessário, propor mudanças no rumo ou curso dessas ações (variável dependente)" (SOUZA, 2007, p.69). A autora ressalta que, além dos governos, outros segmentos se envolvem na sua formulação e desenvolvimento, como: grupos de interesse e movimentos sociais, em que cada qual atua com "[...] maior ou menor influência a depender do tipo de política formulada e das coalizões que integram o governo [...]" (SOUZA, 2007, p.72).

As políticas públicas tomam a forma de programas, projetos, leis, campanhas e subsídios governamentais em várias áreas, como: Saúde, Educação, Esporte e Lazer, Cultura, Economia, Meio Ambiente, Emprego e Renda, Segurança, Habitação, Assistência Social, entre outras possibilidades. 0 conceito de política pública é "[...] transversal a diversas áreas ou setores de intervenção pública" (SECCHI, 2013, p.14).

1 Com base na teoria dos campos de Bourdieu, a partir das esferas do campo político e do campo esportivo, "[...] delimita-se uma intersecção que é representada pelas políticas públicas do esporte. Essa intersecção é identificada pela composição do subcampo das políticas públicas para o esporte e construídas nas disposições das instituições, agentes, ofertas e demandas sociais" (MEZZADRI; SILVA, 2014, p. 21). 
Em português, a palavra política tem um significado abrangente, porém em inglês há diferenciação dos termos polity, politics e policy. Polity relaciona-se à estrutura do sistema político, sua organização e dimensão institucional. Politics trata da dinâmica política, conflitos, disputas, coalizões e barganhas no que se refere à sua dimensão processual. Policy refere-se à dimensão material, ao conteúdo da política propriamente dita, leis, programas, projetos.

As políticas públicas para pessoas com deficiência, historicamente, foram criadas sob os vieses da caridade, do assistencialismo e do protecionismo. Mas, a partir de 1970, com a mobilização desse grupo em torno de seus direitos e da declaração do Ano Internacional da Pessoa Portadora de Deficiência (1981) pela Organização das Nações Unidas (ONU), as políticas têm sido debatidas sob a ótica dos direitos humanos, da necessidade de acesso a educação, trabalho, saúde, acessibilidade, cultura, esporte e lazer, entre outros âmbitos da vida social.

Ao se propor políticas públicas para esse grupo, deve-se buscar o equilíbrio entre o geral e o específico, pontos onde se estabelece a tensão, visto que as políticas públicas precisam ter abrangência para atender à diversidade social e capacidade de se adaptar às especificidades e diferenças da população (PINHEIRO, 2003). As políticas também devem ser intersetoriais, pela complexidade e diversidade do ser humano e de suas necessidades.

Para Pantano (2008), a diversidade deve ser valorizada como parte da condição humana, isso significa que o grupo populacional possui demandas e necessidades específicas que precisam ser atendidas para que possa participar socialmente. Nesse sentido, é essencial pensar a deficiência não apenas como condição biológica e individual, mas como uma questão social e política, conforme o modelo social ${ }^{2}$, considerando que seus determinantes são resultantes da interação do indivíduo (fatores biológicos), ambiente (acessibilidade) e sociedade (estigmas e preconceitos).

A Constituição Federal de 1988 representa um marco no reconhecimento dos direitos das pessoas com deficiência, tratados transversalmente ao longo do texto constitucional. Durante a sua discussão, os movimentos de luta das pessoas com deficiência foram contra 0 capítulo constitucional intitulado "Tutelas Especiais", por considerá-lo discriminatório (BRASIL, 2010).

Em âmbito internacional, a Convenção sobre os Direitos das Pessoas com Deficiência (CDPD), proposta, desenvolvida e aprovada pela ONU e ratificada pelo Brasil em 2007, representa uma baliza para os direitos humanos das pessoas com deficiência ao apoiar e defender os direitos civis, culturais, políticos, sociais e econômicos. A CDPD pretende "[...] promover, proteger e assegurar o exercício pleno e equitativo de todos os direitos humanos e liberdades fundamentais por todas as pessoas com deficiência e promover o respeito pela sua dignidade inerente" (BRASIL, 2007, p. 16). A CDPD foi aprovada no Brasil por meio do Decreto Legislativo $n^{\circ}$ 186, de 9 de julho de 2008, e promulgada pelo Decreto $n-6.949$, de 25 de agosto de 2009, tendo equivalência à emenda constitucional.

Na CDPD, o Artigo 30 - "Participação da vida cultural e em recreação, lazer e esporte" - aponta a necessidade de incentivar e promover a maior participação das pessoas com deficiência ao assegurar a oportunidade de organizar, desenvolver e participar de atividades esportivas, recreativas, turísticas e de lazer, inclusive no sistema escolar (BRASIL, 
2007). Contudo, salienta ser essencial garantir a acessibilidade aos locais, prover instrução, treinamento e recursos adequados aos profissionais. A Lei Brasileira de Inclusão da Pessoa com Deficiência, Lei n-13.146, de 6 julho de 2015, vai ao encontro das propostas da Convenção, reafirmando o direito das pessoas com deficiência. No Capítulo IX - "Do direito à cultura, ao esporte, ao turismo e ao lazer" -, define o número de vagas a serem reservadas às pessoas com deficiência e mobilidade reduzida, segundo o número de lugares disponíveis em teatros, cinemas, estádios, ginásios de esporte, locais de espetáculo, conferências e similares, onde os assentos reservados devem estar distribuídos no recinto, ter boa visibilidade e estar próximos a corredores sinalizados, evitando-se áreas segregadas e obstrução de saídas, conforme as normas de acessibilidade (BRASIL, 2015).

O Plano Nacional dos Direitos da Pessoa com Deficiência - Plano Viver sem Limite, instituído pelo Decreto $n^{0}$ 7.612, de novembro de 2011, propõe ações direcionadas à superação de problemas, tais como: a burocratização de alguns serviços, a precária articulação entre órgãos e políticas públicas e a falta de espaços que promovam a participação popular (BRASIL, 2011). É composto por quatro eixos: 1. Acesso à educação; 2. Inclusão Social; 3. Acessibilidade e 4. Saúde. Embora não aborde diretamente a questão do esporte, no eixo Acessibilidade há o Programa Nacional de Inovação em Tecnologia Assistiva com duas linhas: 1. Inovação em tecnologia assistiva e 2. Desenvolvimento de equipamentos de treinamento e prática de esportes paralímpicos (BRASIL, 2013).

Nos últimos anos, destaca-se também a realização das Conferências Nacionais dos Direitos da Pessoa com Deficiência (2006, 2008, 2012 e 2016), como espaços de discussão entre as pessoas com deficiência, familiares, profissionais e gestores públicos.

Com relação à Política Nacional do Esporte, é dever do Estado fomentar, como direito de cada um, o esporte e o lazer, conforme artigo 217 da Constituição Federal de 1988. Nessa política, esporte e lazer são possibilidades de promoção da saúde, inclusão social, desenvolvimento humano e de identidade cultural, organizados por meio de gestão democrática e participativa (BRASIL, 2005). Aqui, compreende-se o esporte nas vertentes educacional, participativa e de alto rendimento.

Como apresentado, há políticas públicas (policy) em âmbito nacional que tratam do direito de participação das pessoas com deficiência em atividades esportivas e de lazer, seja como organizadores, espectadores ou participantes. A partir desses elementos, discutimos polity, politics e policy de um município e a organização de sua policy network, isto é, as redes formadas para a construção de determinada política pública. Segundo Secchi (2013), atores públicos, privados e demais atores organizados se estruturam em torno de crenças e interesses compartilhados, na forma de redes que são, predominantemente, informais e dinâmicas, relacionadas a determinado tema em um dado momento, e as políticas públicas (policy) delas resultantes são sempre fruto de interações complexas entre os atores.

0 delineamento deste estudo se deu em três etapas: 1. Levantamento de referencial teórico, documentos e marcos jurídicos internacionais, nacionais e do município estudado; 2. Compreensão da polity, isto é, como a estrutura política estava organizada no município e 3. Mapeamento das atividades realizadas e da policy network. Para tanto, foram realizadas entrevistas com representantes de estruturas de governo, pessoas atuantes no campo e profissionais dos programas físico-esportivos identificados. Posteriormente, foi realizado 0 reconhecimento dos locais onde se desenvolviam as atividades. 
O município estudado, conforme o Censo 2010, tem 221.950 habitantes, dos quais $38.808(17,49 \%)$ apresentam alguma deficiência. No Brasil e no estado de São Paulo, 23,9\% e 22,6\% da população apresentam alguma deficiência, respectivamente (INSTITUTO BRASILEIRO DE GEOGRAFIA E ESTATÍSTICA, 2014).

Inicialmente, foram entrevistados os representantes da Secretaria Municipal de Esporte e Lazer (SMEL), da Secretaria Municipal de Cidadania e Assistência Social (SMCAS), da Secretaria Municipal de Saúde (SMS) e da Secretaria Municipal de Educação (SME). As duas primeiras por terem relação direta com as políticas de esporte e de atenção às pessoas com deficiência (polity), as demais por disporem de locais de atendimento distribuídos em regiões periféricas e de profissionais de Educação Física ou programas de atividade física, 0 que a priori poderia contribuir para desenvolver atividades físico-esportivas às pessoas com deficiência. Foram entrevistados 11 gestores e cinco profissionais dos programas esportivos adaptados. Ao todo, foram identificados cinco locais como pertencentes à policy network, além das quatro secretarias municipais citadas, conforme Figura 1.

Figura 1 - Representação da policy network.

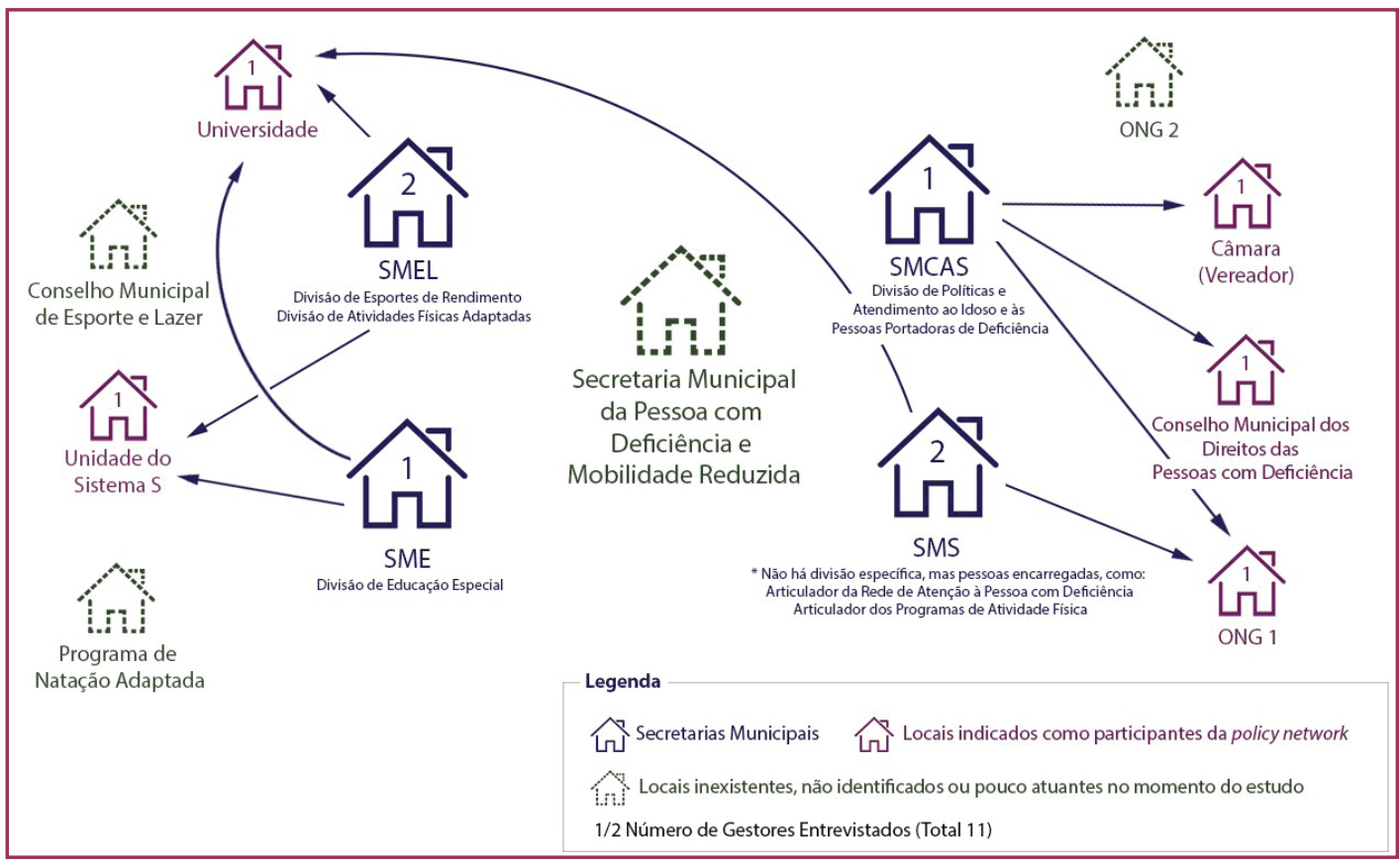

Fonte: Elaborado pelas autoras.

Entre os entrevistados havia gestores sem ensino superior completo, um pertencia à SMEL e três, aos demais locais integrantes da policy network. Três gestores tinham familiares com deficiência e um gestor era cadeirante, o que lhes dava proximidade com a questão. Dos 11 gestores entrevistados, quatro possuíam cursos na área de gestão e quatro na atenção à pessoa com deficiência. Contudo, as informações específicas sobre esse público não eram de seu conhecimento. Em muitos casos, a forma de organizar a estrutura da gestão e 0 conhecimento/habilidade dos gestores interferiram diretamente na articulação da rede. A maioria dos cinco profissionais entrevistados possuía o mesmo perfil: pessoas mais velhas, com anos de graduação e atuação na área de atividade física adaptada e conhecimento na modalidade esportiva, mas sem formação para atuar com pessoas com deficiência. Em princípio, a trajetória 
de todos não se deu por escolha, mas pela necessidade de acompanhamento desse público, com exceção de dois profissionais que cursavam pós-graduação na área e estavam ligados ao projeto de extensão da universidade.

Durante o estudo, o Conselho Municipal de Esporte e Lazer esteve pouco atuante, assim como a ONG 2, identificada após o término da pesquisa e que, embora tivesse anos de atuação, não estava articulada à policy network. $O$ caráter informal e dinâmico e a constante reconfiguração dos atores da rede se confirmaram. Por exemplo: em 2014, tem início o Programa de Natação Adaptada; em 2016, o vereador, pai de dois filhos com deficiência, termina seu mandato; em 28 de junho de 2016, em contrapartida, é criada a Secretaria Municipal da Pessoa com Deficiência e Mobilidade Reduzida, que reorganiza a estrutura da policy network ao concentrar as ações às pessoas com deficiência em diversos âmbitos com as atribuições de:

[...] assegurar o pleno exercício dos direitos individuais e coletivos das Pessoas com Deficiência. Elaborar, desenvolver, acompanhar, orientar a execução, pela Administração Pública Municipal, de planos, programas e projetos voltados para a inclusão da Pessoa com Deficiência, bem como fomentar políticas públicas de inclusão e acessibilidade de modo a articular com as diferentes esferas de governo estabelecendo parcerias com sociedade civil, iniciativas públicas, privadas e de terceiro setor no sentido de desenvolver ações que garantam os valores básicos da igualdade de tratamento e oportunidade, de justiça social, do direito à dignidade da pessoa humana e do bem-estar (PREFEITURA MUNICIPAL DE SÃO CARLOS, 2017, online) $)^{3}$.

Ao analisar o processo de implantação dessa Secretaria, observam-se fatores relacionados à dinâmica política (politics), marcada por lutas, disputas, coalizões e barganhas. Como pesquisadora e observadora externa à estrutura de governo, infelizmente não foi possível detalhar com precisão essa dinâmica. Outro limitador para o estudo foi o pouco tempo de atuação dos gestores comparativamente ao dos profissionais ligados aos programas esportivos, o que em alguns momentos resultou em informações conflitantes entre os interlocutores. Contudo, observou-se que o fato de os governos municipal e estadual pertencerem ao mesmo partido político favoreceu o diálogo entre as esferas de governo e a criação da secretaria, que havia sido anunciada em julho de 2013 e se efetivou próximo ao término da gestão municipal.

A mobilização popular por meio de abaixo-assinado foi fundamental nesse processo. Além da secretaria, se reivindicava a implantação de uma unidade de reabilitação, hoje ainda em negociação. A mobilização também evitou que cargos da secretaria fossem utilizados para acomodação política, e os nomeados foram pessoas com e sem deficiência atuantes no debate e lutas em defesa dos direitos desse grupo populacional.

Quanto à secretaria, os atores públicos que se destacaram foram o prefeito e o vereador. Entre os atores organizados estavam a ONG 1 e a sociedade civil que fomentou 0 abaixoassinado. Já o Conselho Municipal da Pessoa com Deficiência (CONDEF) se estabeleceu na intersecção entre representantes das estruturas de governo, associações, ONGs e sociedade civil.

Durante a pesquisa, o CONDEF se organizava de forma a fomentar a representação do governo e sociedade civil e, assim, viabilizar-se como espaço democrático e representativo, pois até aquele momento seus membros eram majoritariamente funcionários das secretarias municipais. Das quatro pessoas com deficiência (uma pessoa surda e três cadeirantes), 
participantes assíduas das reuniões, apenas uma era conselheira e, portanto, com direito a voto. $O$ fato desta pessoa também atuar como conselheira no Conselho Estadual para Assuntos da Pessoa Portadora de Deficiência permitiu maior articulação. Inclusive, em março de 2014 a primeira reunião itinerante desse Conselho ocorreu no município estudado como parte da proposta de descentralizar as discussões da capital, promover maior participação de outras regiões e proporcionar maior proximidade com problemas e as realidades locais.

A participação popular nas decisões políticas caracteriza-se como espaço legítimo para o exercício da cidadania e democracia e persistem diferenças entre as políticas públicas desenvolvidas para a população e as desenvolvidas com a população. Naquelas, tendem à postura conformista e dependente do Estado, enquanto nestas, há participação conjunta nas decisões, sendo a população coautora das políticas (STIGGER, 1998). Starepravo e Mezzadri (2007, p.195) afirmam que "[...] pela inacessibilidade aos mecanismos de produção no campo político, a maioria das pessoas fica à margem do processo de decisão política, tendo que se contentar com o que lhes é disponibilizado pelas unidades produtoras". Vale salientar que a organização dos espaços políticos é essencial para a participação popular nos processos decisórios. Essa questão é ampla e envolve a educação da população não só para atuar no cenário político, como também lidar com a descrença e estigma atribuídos à política e a tudo que a ela se relaciona.

Apesar das dificuldades apresentadas no município estudado, a policy network mostrou-se articulada na luta por direitos, o que resultou no Código Municipal de Acessibilidade e Mobilidade Reduzida (Lei no 17.649, de 2 de dezembro de 2015), de autoria do vereador mencionado, que se constitui como política pública (policy) relevante para (re)afirmar o direito das pessoas com deficiência, inclusive no esporte e lazer. Em 16 de março de 2016, a aprovação da Lei no 17.759 incluiu no calendário anual de eventos do município competições esportivas destinadas aos estudantes com deficiência da rede de ensino (SÃO CARLOS, 2016). Em 10 de dezembro de 2016, foi inaugurada a academia adaptada ao ar livre, proposta discutida desde 2013. Embates contra a implantação de tal estrutura em local segregado possibilitaram sua instalação em praça reconhecida pela população como espaço público para prática de atividade física. A policy network atuou junto à Secretaria de Estado dos Direitos da Pessoa com Deficiência para a captação de recursos e para que a proposta fosse inclusiva e coerente com o exercício de direitos.

Espaços e programas inclusivos que permitam a participação de pessoas com e sem deficiência são essenciais, reafirmam o direito das pessoas de participarem da vida social e que a deficiência é uma condição que faz parte da diversidade humana. Cabe aos gestores e profissionais pensarem as políticas públicas com base no modelo social de concepção da deficiência, nos marcos legais e nas necessidades gerais e específicas da população.

Neste estudo, observou-se que, nos programas esportivos que atendem à população em geral, a participação de pessoas com deficiência foi mínima. Há falta de informações sistematizadas pelos órgãos gestores, as atividades estão dispersas geograficamente e não se configuram como uma política pública estruturada e articulada internamente nas unidades de serviço (escolas, unidades básicas de saúde, centros esportivos) embora haja uma diretriz para 0 atendimento desse público. A responsabilidade está a cargo do profissional que está na ponta, que busca articulação intersetorial, possibilitando, por exemplo, que a pessoa com deficiência que realizou o processo de reabilitação no serviço de saúde conheça os programas esportivos adaptados. 
Nos programas esportivos para o público em geral, embora a prática seja inclusiva, o participante com deficiência normalmente se depara com espaços sem acessibilidade, com profissionais despreparados e com estigmas e preconceitos com relação à sua deficiência. É natural que haja rotatividade e pouca vinculação dessas pessoas em tais programas, conforme relato de profissionais responsáveis pelo Serviço de Orientação à Atividade Física da SMEL, pelos Grupos de Atividade Física da SMS e pela prática esportiva no ambiente escolar. Por outro lado, embora a prática seja segregada, nos programas esportivos adaptados as pessoas com deficiência têm a possibilidade de se encontrar com seus pares, de criar identidade e sentido de pertencimento muito maior ao ser reconhecidas como um grupo de paratletas.

O mapeamento das atividades, registrado no Quadro 1 (ver na próxima página), identificou três programas esportivos adaptados e cinco modalidades (atletismo, natação, futebol de 5, goalball e handebol em cadeira de rodas). Natação e atletismo foram as mais frequentes, provavelmente por serem modalidades individuais, que não necessitam muitas adaptações ou recursos financeiros. No entanto, o número de participantes nos programas foi pequeno, muitos frequentavam mais de um deles e se tornou evidente o reduzido número de meninas/mulheres participantes, provavelmente por enfrentarem maiores barreiras à participação e estarem mais sujeitas ao estigma, à superproteção e/ou ao isolamento social. Esse dado é semelhante ao encontrado na população em geral em que as mulheres são mais sedentárias no lazer.

Ao se planejar as políticas públicas, é necessário considerar a especificidade de determinados grupos populacionais. A linha é tênue e no equilíbrio entre o geral e o específico se estabelece 0 desafio.

As atividades da SMEL estavam voltadas para o rendimento e os paratletas participavam de competições regionais representando o município. $\mathrm{O}$ atletismo acontecia em parceria com a Associação de Atletismo local, que recebia repasses financeiros da secretaria, verbas parlamentares e patrocínios para a manutenção das atividades. A natação era realizada em clube, parceiro da SMEL na cessão do espaço físico.

A SME possuía o programa mais antigo voltado ao esporte adaptado. Nele eram oferecidos transporte porta a porta e alimentação aos participantes. As atividades eram voltadas ao esporte lazer/participação e se iniciaram ao final dos anos 1990, para atender à demanda educacional apresentada após surto de meningite, que deixou sequelas de surdez em diversas crianças. Como à época não havia política de inclusão no ensino regular, a SME firmou parceria com o departamento de Educação Especial da universidade para atender as crianças no contraturno escolar, inclusive com aulas de Educação Física. Nesse contexto, foi realizado, em 1997, o primeiro Simpósio de Atividade Física Adaptada na tentativa de oferecer conhecimento teórico e experiências práticas para a atuação profissional. A iniciativa ainda hoje é conduzida pela unidade do sistema S com apoio da SME e da universidade.

A universidade possui uma das poucas graduações em educação especial do país e 0 primeiro e único programa de pós-graduação especificamente em educação especial, criado nos anos 1980. Hoje a Lei no 9.394, de 20 de dezembro de 1996 - Lei de diretrizes e bases da educação - contribui para o processo de inclusão de estudantes com deficiência na rede regular de ensino e, consequentemente, nas aulas de Educação Física, fato que demanda melhor formação e capacitação desses profissionais. 


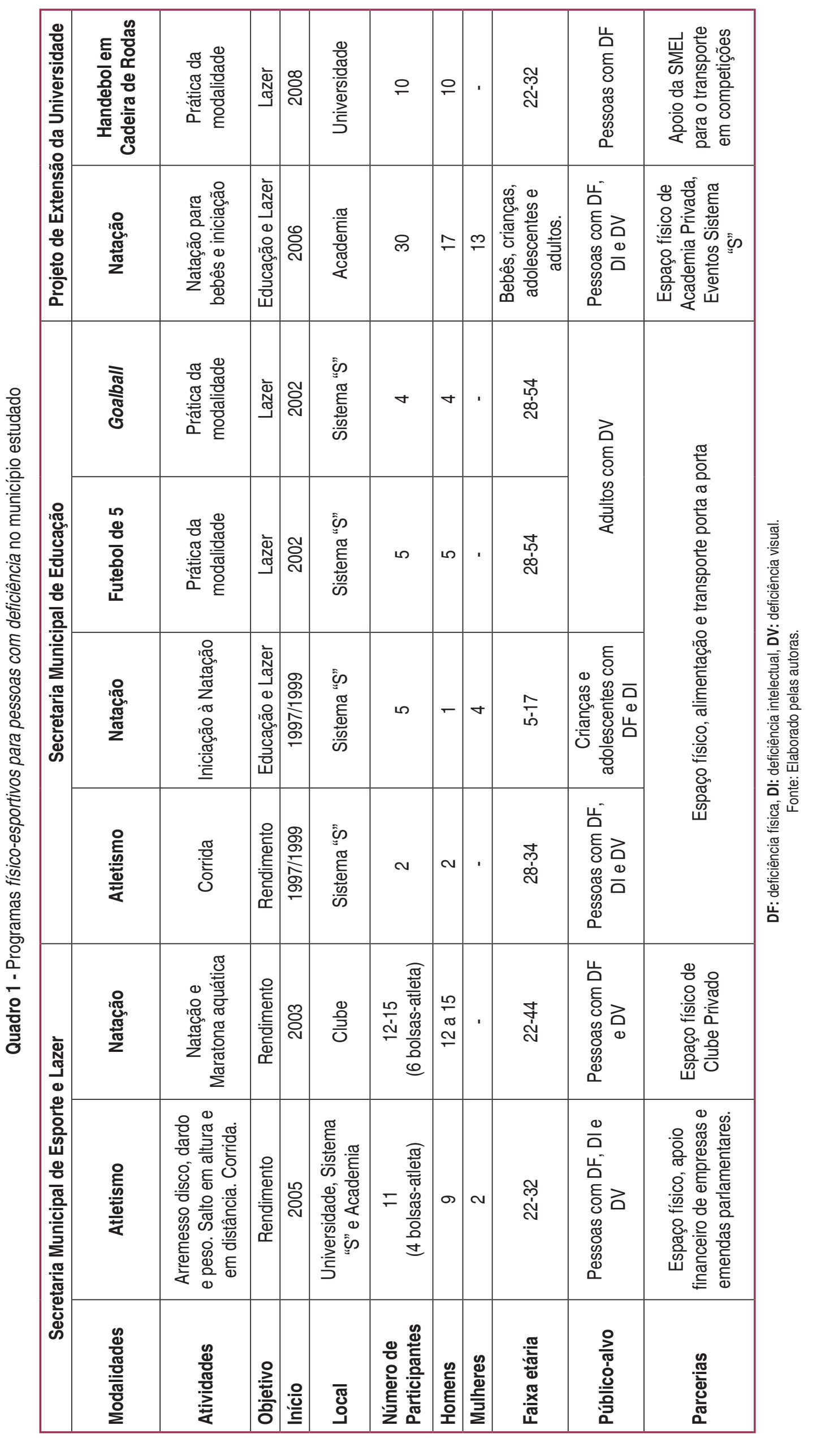


Nesse sentido, o programa de extensão da universidade do departamento de Educação Física possibilita 0 atendimento à comunidade, a realização de pesquisa e a formação prática dos estudantes. As aulas de natação eram realizadas em espaço cedido por uma academia, pois a piscina da universidade é aberta e sem aquecimento. $O$ handebol em cadeira de rodas era conduzido por alunos de pós-graduação que tinham proximidade com a modalidade. Embora o foco não fosse o rendimento, quando possível, o time participava de competições. Um atleta e o técnico compuseram a seleção brasileira.

A partir do contexto estudado, alguns elementos se mostram essenciais na constituição de programas físico-esportivos para as pessoas com deficiência. São eles: 1. Compreensão do esporte de maneira ampla em todas as suas vertentes (alto rendimento, educacional e participativa) como direito de todos; 2. Aparatos legais de afirmação dos direitos das pessoas com deficiência; 3. Espaços de discussão e participação popular na política; 4. Parcerias e articulação entre instituições, terceiro setor e poder público; 5. Acessibilidade aos locais de prática esportiva e ao transporte; 6 . Atores engajados na policy network; 7. Dados sistematizados sobre o perfil das pessoas com deficiência, 8. Políticas intersetoriais; 9. Conhecimento técnicocientifico e 10. Capacitação de gestores e profissionais.

\section{CONSIDERAÇÕES FINAIS}

O aparato legal relacionado à afirmação de direitos das pessoas com deficiência e o contexto dos megaeventos esportivos no país contribuíram para o aumento das políticas públicas, financiamentos, infraestruturas, pesquisas e capacitação profissional no setor. Contudo, estudos sobre políticas públicas de esporte e lazer ainda são incipientes, principalmente no que se refere às pessoas com deficiência.

O presente estudo buscou contribuir para a compreensão do cenário a partir do mapeamento dos espaços, atores e suas inter-relações na policy network em dado município. Foi possível identificar como pontos-chave para a constituição de políticas e programas na área o surgimento de demanda a organização social e a sensibilidade dos órgãos competentes para compreendê-la como um problema a ser resolvido e, assim, se articularem condições, instituições e pessoas capazes do enfrentamento da questão. Contudo, não foi observada uma política intersetorial articulada e as relações entre os atores foram, predominantemente, de maneira informal. Outros fatores limitantes foram a falta de dados sistematizados pelas secretariais relacionados às pessoas com deficiência, informações conflitantes entre os grupos de gestores e profissionais entrevistados, bem como a dinâmica da policy network. Novos estudos podem aprofundar essas e outras dimensões em diferentes contextos.

\section{REFERÊNCIAS}

BRASIL. Ministério do Esporte. Política Nacional do Esporte. Brasília, 2005.

BRASIL. Secretaria Especial dos Direitos Humanos. Convenção sobre os Direitos da Pessoa com Deficiência. Brasília, 2007. 
BRASIL. Secretaria de Direitos Humanos. Secretaria Nacional de Promoção dos Direitos da Pessoa com Deficiência. História do Movimento Político das Pessoas com Deficiência no Brasil. Brasília, 2010.

BRASIL. Lei no 9.394, de 20 de dezembro de 1996. Estabelece as diretrizes e bases da educação nacional. Diário Oficial da República Federativa do Brasil, Brasília, DF, 23 dez. 1996, seção1, p.27833-27841.

BRASIL. Lei n-7.612, de 17 de novembro de 2011. Institui o Plano Nacional dos Direitos da Pessoa com Deficiência: Plano Viver sem Limite. Diário Oficial da República Federativa do Brasil, Brasília, DF, 18 nov. 2011, seção1, p.12-13.

BRASIL. Secretaria de Direitos Humanos da Presidência da República (SDH/PR). Secretaria Nacional de Promoção dos Direitos da Pessoa com Deficiência (SNPD). Viver sem Limite: Plano Nacional dos Direitos da Pessoa Com Deficiência. Brasília, 2013.

BRASIL. Lei n- 13.146, de 6 de julho de 2015. Institui a Lei Brasileira de Inclusão da Pessoa com Deficiência (Estatuto da Pessoa com Deficiência). Diário Oficial da República Federativa do Brasil, Brasília, DF, 07 jul. 2015, seção 1, p. 2-11.

INSTITUTO BRASILEIRO DE GEOGRAFIA E ESTATíSTICA. Censo Demográfico e Contagem da População. Sistema IBGE de Recuperação Automática SIDRA. Disponível em: <http://www.sidra. ibge.gov.br/bda/tabela/protabl.asp?c=3426\&z=cd\&0=13\&i=P> Acesso em: 20 ago. 2014.

MATIAS, Wagner Barbosa et al. A lei de incentivo fiscal e o (não) direito ao esporte no Brasil. Movimento, v.21, n.1, p.95-110, jan./mar. 2015.

MEZZADRI, Fernando Marinho; SILVA, Marcelo Moraes e. Desenvolvimento de um método para as pesquisas em políticas públicas de esporte no Brasil: uma abordagem de pesquisa mista. In: MEZZADRI, Fernando Marinho (Org.). Políticas públicas e esporte. Várzea Paulista: Fontoura, 2014. p.15-31.

PANTANO, Liliana. Discapacidad: conceptualización, magnitud y alcances. Apuntes para el mejoramiento de las prácticas en relación a las personas con discapacidad. Centro de Investigaciones Sociológicas. Departamento de Sociología. FCSE. UCA/CONICET. Documento de trabajo, 2008. Disponível em: < https://www.santafe.gov.ar/index.php/educacion/content/download/127521/630945/ file/Discapacidad-\%20\%20conceptualizaci+',n,\%20magnitud\%20y\%20alcances.pdf > Acesso em: 1 out. 2018.

PINHEIRO, Humberto Lippo. As políticas públicas e as pessoas portadoras de deficiência. In: SILVA, Shirley; VIZIM, Marli (Orgs). Políticas públicas: educação, tecnologias e pessoas com deficiências. Campinas: Mercado de Letras: Associação de Leitura do Brasil, 2003. p.101-123.

PREFEITURA MUNICIPAL DE SÃO CARLOS. Secretaria Municipal da Pessoa com Deficiência e Mobilidade Reduzida. São Carlos, 2017. Disponível em: <http://www.saocarlos.sp.gov.br/index.php/ secretarias-municipais/secretaria-pessoa-com-deficiencia-e-mobilidade-reduzida.html> Acesso em: 10 abr. 2017.

SÃO CARLOS. Câmara Municipal. Lei no 17.649, de 2 de dezembro de 2015. Institui o código municipal de acessibilidade e mobilidade reduzida. Diário Oficial, São Carlos, SP, 2 dez. 2015. seção1, p. 1-21.

SÃO CARLOS. Câmara Municipal. Lei no 17.759, de 16 de março de 2016. Inclui o "Jogos da Primavera" e o "Primavera Especial" no calendário oficial de eventos do município e dá outras providências. Diário Oficial, São Carlos, SP, 20 mar. 2016. seção1, p. 1. 
SECCHI, Leonardo. Políticas Públicas: conceitos, esquemas de análise, casos práticos. 2.ed. São Paulo: Cengage Learning, 2013.

SOUZA, Celina. Estado da arte da pesquisa em políticas públicas. In: HOCHMAN, Gilberto; ARRETCHE, Marta; MARQUES, Eduardo Cesar (Org.). Políticas públicas no Brasil. Rio de Janeiro: Fiocruz, 2007. p.65-86.

STAREPRAVO, Fernando Augusto. Caracterizando o subcampo político/burocrático do esporte e lazer no Brasil. In: MEZZADRI, Fernando Marinho (Org.). Políticas públicas e esporte. Várzea Paulista: Fontoura, 2014. p.33-48.

STAREPRAVO, Fernando Augusto; MEZZADRI, Fernando Marinho. Conselhos Municipais de Esporte e Lazer e outras formas de participação direta no estado do Paraná. Coleção Pesquisa em Educação Física, v.5, n.1, p.193-198, 2007.

STAREPRAVO, Fernando Augusto; NUNES, Ricardo Sonoda; MARCHI JR., Wanderley. Agenda de pesquisa em políticas públicas de esporte e lazer: uma leitura a partir do GTT de Políticas Públicas no XV Congresso Brasileiro de Ciências do Esporte. In: CONGRESSO BRASILEIRO DE CIÊNCIAS DO ESPORTE, 16., CONGRESSO INTERNACIONAL DE CIÊNCIAS DO ESPORTE,3. Anais... Salvador: Colégio Brasileiro de Ciências do Esporte, 2009. p.1-14.

STAREPRAVO, Fernando Augusto; SOUZA, Juliano de; JÚNIOR, Wanderley Marchi. Políticas Públicas de Esporte e Lazer no Brasil: uma Proposta Teórico-Metodológica de Análise. Movimento, v.17, n.3, p. 233-251, jul./set. de 2011.

STIGGER, Marco Paulo. Políticas sociais em lazer, esportes e participação: uma questão de acesso e de poder; ou subsídios para tomar uma posição frente à pergunta: "são as políticas públicas para educação física, esportes e lazer, efetivamente políticas sociais?" Motrivivência, v.10, n.11, p. 83-96, jul.1998. 
Apoio:

Universidade Federal de São Carlos; Prefeitura de São Carlos; CAPES 